for child psychiatry and psychotherapy were on a sessional basis, not as a full-time attachment.

No one is going to offer any psychiatry tutor working in a District General Hospital another registrar's post to ensure ample numbers so as to give full six-month placements in all desirable settings.

We are going to have to try and ensure comprehensive training by attachments on a sessional basis to as many areas of psychiatric interest as is possible.

The College's demands for a fixed stereotyped three-year training programme is making our tasks very difficult, and we risk not being approved with posts losing recognition, just as a Local Elderly Mentally Infirm Unit is set up sixty miles from the nearest mental hospital, and fifty miles from the nearest psychogeriatrician.

Can the College not think afresh about the training of psychiatric junior staff in District General Hospitals Units, and would they not consider limited or partial approval for two years in such a setting where there is no mental hospital handy to complete the desirable three-year experience? Might posts not be approved, as in other specialties, rather than full programmes?

D. H. MORgaN

Chatterton House

King's Lynn, Norfolk

\section{College recognition of psychiatric tutors}

DeAR SIR

The principles and criteria recently approved by Council (Bulletin, February 1982, 6, 24) for the recognition of psychiatric tutors are welcome, but there are areas to which the College should give further thought:

1. In order that the interests of the majority of psychiatric patients are not disadvantaged, should there not also be a psychiatric tutor (specialty) in general adult psychiatry?

2. If the reports on trainees which the tutor is expected to prepare are of a written nature this should be indicated in the Statement on Approval which is sent to hospitals before Approval visits. Tutors and Approval Exercise Visitors in the past have disagreed on the practical interpretation of the present wording-that the tutor is 'responsible for collating the periodic assessment reports on trainees'. Many tutors and Approval Teams would also welcome comment from the College as to the form such reports should take.

3. Is not the amount of time to be allocated to the tutor best left for individual Divisions of Psychiatry to decide, on the basis of local arrangements and conditions? The document does acknowledge that tutorial duties vary between Regions but nevertheless states that 'a minimum of two sessions per week' should be allocated for tutorial duties. With consultants keen to participate in teaching and well motivated trainees, two sessions per week, for duties which are mostly of an organized nature, may seem unduly generous, particularly at times when there is any difficulty in meeting routine service commitments. In such circumstances there will be a natural increasing tendency to off-load teaching responsibilities on to the tutor because of his specific allocation of time for such. This would narrow the breadth of teaching experience to which trainees would be exposed.

J. Kenneth Binns

\section{Leverndale Hospital}

Glasgow

\section{The College and South Africa}

DeAR Sir

Dr Hemphill (Bulletin, March 1982, 6, 44), like other white psychiatrists in South Africa before him (Gillis, 1977), chooses to ignore the main body of evidence in support of allegations of political abuses in the field of mental health there. Most of the evidence for political misuse of psychiatry in South Africa was summarized in my letter (Bulletin, November 1980, 171), and this was based on reports published by the World Health Organisation and the American Psychiatric Association. Apart from his ritual protestations, Dr Hemphill's attempt to discredit my motives and doubt the credibility of the accusations is not supported by any new facts.

His claim that South African mental health legislation is free of discriminatory provisions is irrelevant. It is also misleading, because he fails to mention that the apartheid system, under which all South African laws are enacted, is based on direct discrimination on the basis of skin colour alone. His suggestion that abuses do not exist because no one is authorized to misuse psychiatry is as credible as denying political bias in Soviet psychiatry because there are no laws in the Soviet Union which specifically invest psychiatrists with additional responsibilities to detain political dissenters in mental institutions. Dr Hemphill's naïve belief that practice of psychiatry, or for that matter medicine, could be free of prevailing social and political considerations can only be attributed to a refusal to recognize the realties of the apartheid system.

I referred to an article in the Johannesburg Sunday Times entitled 'Millions out of Madness' (27 April, 1975) because this was one of the first reports to accuse the minority government of a profit-incentive business deal with a private accountancy film, Smith, Mitchell and Company, which led to sub-standard care for black psychiatric patients. Miss de Villiers described the appalling conditions in mental institutions for blacks as 'a South African version of the Dickensian workhouse, an uncomfortable reminder of the bad days in Bedlam ...'

If $\mathrm{Dr}$ Hemphill really believes that there is no differentiation in the standards of psychiatric care according to the 